\title{
A "Preciosa" educação como caminho para a emancipação
}

Vanessa Raianna Gelbcke ${ }^{1}$

\section{Resumo:}

O campo da cinematografia tem possibilitado uma gama de reflexões que nos permite compreender aspectos da realidade social que muitas vezes passam despercebidos, ou não são problematizados. Isto é, a cinematografia age como um espelho, refletindo a vida em sociedade. A educação, em especial a educação escolar, possui uma filmografia significativa que nos permite compreender, ou olhar com outros olhos, o processo educacional e as relações que se estabelecem dentro das instituições. Nesta perspectiva, o presente artigo, busca problematizar a educação espelhada no filme "Preciosa: uma história de esperança". Pode-se constatar que a instituição representada nesta trama, revela a incapacidade de a escola regular atender sujeitos tão peculiares como a jovem Preciosa, que aos 16 anos, ainda não havia aprendido a ler e escrever, devido à educação a qual estava submetida. Encontrando como solução, pelo sistema educacional, a transferência para uma instituição alternativa. Por outro lado, a trama também revela o papel que a educação exerce como emancipadora/libertadora de situações de opressão e vulnerabilidade da protagonista. Desta forma, pretende-se analisar os significados da instituição escolar apresentados no filme.

Palavras-chave: Educação, Análise cinematográfica, Emancipação.

\footnotetext{
${ }^{1}$ Graduanda do Curso de Pedagogia da Universidade Federal do Paraná e integrante do Grupo de Pesquisa Observatório do Ensino Médio da UFPR. E-mail: vanessagelbcke@gmail.com
} 
As formas de se observar fatos educativos, dentro das instituições ou fora delas, podem ser descritos de diversas formas, através de pesquisas etnográficas, análises de documentos e também por meio de produções cinematográficas. Estas podem trazer em seus roteiros aspectos presentes na realidade, mesmo filmes de ficção científica, que geralmente abordam situações inusitadas, permitem análises sociológicas interessantes, uma vez que a produção destes está imersa em algum contexto, que será refletido nas cenas dos filmes.

Desta forma, o cinema trouxe a possibilidade de transgredir os limites entre o real e o imaginário, ele consegue expressar situações de sonhos e esperanças, vitórias e derrotas, angústias, injustiças e felicidades presentes na sociedade. Assim, se estabelece uma relação de cumplicidade entre o real e o imaginário, dentro e fora da tela com o espectador. Entretanto pode-se questionar até que ponto o cinema é realidade ou ficção? O cinema estaria refletindo a realidade na forma como ela é vivida? Ou o contrário, o cinema não seria a construção de uma realidade feita pelas mãos dos produtores, que articulam os fatos segundo sua visão de mundo sobre os acontecimentos? Shohat e Stam (2006) discutem que a busca pela representação da verdade, propalada pelos produtores, reflete suas perspectivas particulares sobre as situações/fatos, pois não existem verdades absolutas, mas existem verdades contingentes construídas a partir de visões de mundo de certas comunidades. 
A questão, portanto, não é fidelidade a uma verdade ou realidade preexistente, mas a uma orquestração de discursos ideológicos, e perspectivas coletivas. Se num determinado nível um filme se constitui através de uma prática mimética, ele também é discurso, um ato de interlocução contextualizada entre produtores e receptores socialmente situados. (SHOHAT; STAM 2006, p. 265)

De qualquer forma, pode-se afirmar que o realismo presente nas produções cinematográficas nos passa a ilusão de presenciarmos a última representação da verdade. Este fato nos remete a um dos aspectos que devemos levar em consideração ao analisar uma obra fílmica, em um primeiro momento conhecer em que período histórico ela foi produzida e quem a produziu. Análises anteriores já demonstraram que estas informações nos dão subsídios para se afirmar que o filme, seja qual for, pode ser encarado como testemunho da sociedade que o produziu, como sendo o reflexo das ideologias, dos costumes e das crenças, mas muitas vezes de maneiras metafóricas ou mesmo alegóricas. Outro aspecto importante de ser analisado se refere ao gênero cinematográfico, filmes de documentários, por exemplo, trazem a promessa da abordagem fiel à realidade. Porém segundo Gutfreind (2006, p. 9) este aspecto tem se alterado:

A discussão em torno da representação e de seus diferentes caminhos reflexivos, levou-nos a compreender o cinema como fenômeno de percepção social. Hoje, o olhar do pesquisador não se fixa somente na "natureza" do filme e na relação direta que esse entretém com 
fenômenos específicos, sobretudo com a literatura, mas na apreensão da complexidade do cinema a partir de dois vieses que interagem entre si: um, de valor pragmático, que entende a organização da produção cinematográfica como resultado do meio sociocultural no qual ele se insere, assim como expressão artística autônoma; e outro que compreende o cinema como uma técnica de reprodução cujos desdobramentos e avanços definiram um tipo de experiência constituída através de processos subjetivos.

Com base nesta perspectiva, o presente trabalho busca analisar, brevemente, as representações da educação, em seu sentido amplo, as representações da instituição escolar, bem como seus significados presentes nas produções fílmicas, e em um segundo momento, aprofundar as análises com base nas representações presentes no filme "Preciosa: uma história de esperança" (2009) de Lee Daniels², permitindo uma reflexão sobre a educação de uma jovem negra, obesa, mãe de duas crianças - frutos de estupros praticados pelo seu pai - e analfabeta aos 16 anos. Buscando compreender, que sentidos a escola tinha para essa jovem? Quais os objetivos da educação para a protagonista? Como a instituição a enxergava? Quais os caminhos encontrados pelo sistema educacional descrito no filme? Entre outros questionamentos. Cabe ressaltar que este projeto é um exercício de

\footnotetext{
${ }^{2}$ Lee Louis Daniels nasceu em 1959 na Filadélfia é um ator, produtor de filmes e diretor, mais conhecido por produzir Monster's Ball e dirigir Precious, a adaptação cinematográfica do romance Push, de Sapphire, que recebeu seis indicações ao Oscar, inclusive para Melhor Diretor e Melhor Filme, sendo a segunda vez que um Afroamericano foi homenageado.
} 
análise, feito com o objetivo de alimentar um debate em curso, não pretendendo esgotar todas as problemáticas levantadas no filme.

\section{As representações escolares no cinema}

Longe de se pretender responder a indagação se o cinema representa o real ou a ficção, pode-se asseverar que as representações escolares no cinema contemporâneo abordam de forma contundente as relações estabelecidas dentro e fora das instituições, bem como criam significados para esta. Neste cenário, as produções Hollywoodianas ganham destaque quando o tema é a escola, muitos filmes desta rede possuem a escola como pano de fundo das tramas, algumas vezes como o espaço central, onde as situações mais importantes acontecem ${ }^{3}$. Assim, pode-se perceber que, de maneira geral, os significados transmitidos refletem a ideia de que a escola só é importante e interessante quando os/as estudantes se divertem ou quando estão fora das salas de aula, tais produções representam em geral estudantes de classe média. Entretanto, filmes caracterizados como de superação, com

${ }^{3}$ Cabe ressaltar que as discusões presentes neste artigo, foram construídas em conjunto pelo Grupo de Estudos "Olhares Sobre a Escola", da Universidade Federal do Paraná. Assim, agradeço à Jessica Santos, Débora Tamires Porcel, Marilene Noriko Treider Otani, Marcelo Francisco, Aline Fernanda Carneiro, Andreia Bráz, Ana Caroline Ferraz, Janaína Felicio Stratmam, Claúdia Prestes, Giovana Fraron Oss e a coordenadora Lennita Oliveira Ruggi pela contribuição e socialização de ideias. 
professores idealizados remetem a representação de estudantes de classe baixa.

Robert Bulman, sociólogo que discute as divisões de classe na sala de aula, categoriza as produções cinematográficas hollywoodianas sobre a escola em duas categorias: 1) filmes que representam a população pobre, nestes o/a professor/a aparece como herói/heroína e tem como principal função inserir os/as estudantes no saber escolar e num ethos de classe média. 2) filmes que retratam a classe média, estes não enfatizam o saber acadêmico, sendo a escola um espaço de socialização juvenil, especialmente aquelas localizadas em regiões periféricas. Nestes filmes os/as professores/as não são valorizados/as, pois a ênfase está na construção da identidade. Nas palavras do autor:

In the films based in suburban high schools, academic success is not a central focus of the plot. The suburban school films depict schools less as actual places of learning and more as social spaces where middle-class teenagers search for their identities and struggle with each other for the rewards of social status and popularity. In these films schoolwork is secondary to the real drama of teen angst. (...) Instead of conformity to middle-class values, the suburban school students must reject the conformity of their peers, the culture of popularity, and the constrains of adult order to express their true selves (BULMAN, 2005, p.10). ${ }^{4}$

\footnotetext{
4 "Nos filmes baseados em escolas de subúrbios, o sucesso acadêmico não é o foco central da trama. Os filmes retratam estas escolas menos como lugares reais de aprendizagem e mais como espaços sociais onde os adolescentes da classe média buscam suas identidades e disputam uns com os outros as recompensas por status social e popularidade. Nesses filmes o trabalho escolar é secundário em relação ao 
Com isto, pode-se assegurar que ao analisarmos as produções fílmicas a classe social representada desempenhará papel significativo na construção dos roteiros, determinando qual será a ênfase dada à escola, enquanto instituição, e ao papel do/a professor/a. Filmes como "Escritores da Liberdade" (2007) de Richard LaGravenese, ou mesmo na produção aqui analisada, por exemplo, retratam a classe baixa e os/as docentes desempenham papel crucial na construção indenitária de seus/suas estudantes, assim, identifica-se a imagem do/a docente como um/a profissional que vai além da sua função na escola, estabelecendo elos com seus/suas estudantes fora do âmbito educacional, tentando de todas as formas ajudá-los/as; ou ainda, como o/a professor/a herói/heroína e inovador/a que se desafia ao ensinar estudantes rebeldes, tentando implementar "novos" métodos de ensino, subvertendo a metodologia tradicional.

Quando são analisadas as representações da escola no cinema brasileiro, observa-se a influência hollywoodiana nas produções cinematográficas. Com alguns adendos no tocante à forma de representações expressas, como no caso das produções brasileiras

verdadeiro drama, o da angústia adolescente. (...) Em vez de se conformarem com os valores da classe média, os alunos de escolas de subúrbios devem rejeitar a conformidade de seus pares, a cultura da popularidade, e os constrangimentos da vida adulta para expressar suas verdadeiras identidades." (Tradução da autora) 
"Professora Maluquinha" (2011) de André Alves Pinto e César Rodrigues, ou "As melhores coisas do mundo" (2010) de Laís Bodansky, que podem facilmente ser identificados como brasileiros, a partir do ambiente (cenários) em que se passa a trama. É possível observar em filmes que retratam as escolas brasileiras significados semelhantes aos encontrados nas produções hollywoodianas, principalmente no que se refere à figura idealizada e romantizada do/a docente e o caráter "entediante" da escola enquanto espaço de aprendizado, supervalorizando os momentos de socialização, isto é, os episódios que acontecem fora da sala de aula.

Embora a obra aqui analisada possa permitir um olhar para a questão educacional, o foco central não é a escola. Esta foi produzida dentro de uma perspectiva que buscava enunciar uma história de superação, englobando aspectos presentes no cotidiano de uma adolescente, e a educação escolar se configura como um destes, permitindo, assim, que as características até o momento apontadas possam ser identificadas.

\section{Preciosa: uma história de esperança}

Preciosa: Uma historia de esperança (2009), foi lançado pela Lionsgate e PlayArte, tendo como tema a superação. É uma produção 
dirigida por Lee Daniels, baseada do livro "Push", da poetisa Sapphire (nome artístico de Ramona Lofton), publicado em 1996. A história se passa em 1987, no Harlem, bairro pobre de Nova Iorque, contando a história de uma garota chamada Claireece Precius Jones, uma adolescente de 16 anos, que cresceu em um ambiente hostil onde sofria muitas dificuldades financeiras, além das agressões físicas e verbais da mãe e abusos sexuais do pai, com quem teve dois filhos, Mongo e Abdu. Durante a trama é perceptivel as situações de preconceito pelas quais Preciosa passava, negra, obesa e mãe já na adolescência. Apresenta um perfil introvertido, não gosta de falar sobre certos assuntos, principalmente os referentes à sua vida particular. Quando provocada pela mãe não reage, engole as ofensas e permanece em silêncio. bell hooks ${ }^{5}$, uma escritora negra dos Estados Unidos, alega que o ato de reprimir os sentimentos se caracteriza como uma forma de sobrevivência:

A prática de se reprimir os sentimentos como estratégia de sobrevivência continuou a ser um aspecto da vida dos negros, mesmo depois da escravidão. Como o racismo e a supremacia dos brancos não foram eliminados com a abolição da escravatura, os negros tiveram que manter certas barreiras emocionais. E, de uma maneira geral, muitos negros passaram a acreditar que a capacidade de se conter emoções era uma característica positiva. No decorrer dos anos, a habilidade de esconder e mascarar os

\footnotetext{
${ }^{5}$ A autora prefere que seu nome seja grafado em letras minúsculas por considerar que "o mais importante em meus livros é a substância e não quem sou eu". Para ela, nomes, títulos, nada disso tem tanto valor quanto as ideias.
} 
sentimentos passou a ser considerada como sinal de uma personalidade forte. Mostrar os sentimentos era uma bobagem (hooks, 2000. p 189).

Este ato, de mascarar seus sentimentos, pode ser identificado nos momentos em que Preciosa discute com a mãe. Em uma destas cenas, permanece parada no topo da escada enquanto sua mãe lhe dirige ofensas. A expressão de seu rosto é intensificada pela posição da câmera, que torna a iluminação baixa e sombria, passando ao telespectador a impressão de que a qualquer minuto a protagonista irá se defender, dizer ou fazer algo. Tal atitude incomoda sua mãe que tenta subir a escada rapidamente, pronta para agredir Preciosa, que se direciona ao seu quarto, enquanto a mãe tropeça na escada.

Além da relação difícil com a mãe, pode-se observar que Preciosa não tinha amigos/as, representando, em certa medida, uma adolescente sozinha, que passa por inúmeras situações adversas, apresentadas em geral dentro de casa. Cabe ressaltar que nestas cenas domiciliares a luz é baixa, e o cenário com cores frias, revelando o clima amedrontador e desacolhedor, em contraste com as cenas de fantasia, repleta de cores e luzes. Porém, apesar dos obstáculos encontrados, Preciosa enxerga na educação um caminho de melhorar a sua situação e a de seus filhos, representadas nas cenas em que dialoga com seu filho Abdu - ainda bebê - sobre a importância de se estudar e ser alguém esperto, como dito por ela, enquanto passava a noite na casa de sua professora: "É bom que ele escute elas falarem, porque elas são 
espertas", e ainda, em seus pensamentos narrados, menciona que conta histórias todos os dias para que ele se interesse pela leitura e tenha um futuro, revelando a esperança depositada na educação. Este fato contrasta com a crença na qual foi criada, sua mãe não acreditava na educação, diz repetidas vezes que a filha não aprende nada, considerando a escola como perda de tempo. A própria situação da protagonista revela que a instituição regular peca em aspectos fundamentais da formação do indivíduo, pois é de se esperar que um/a estudante matriculado no colegial saiba ao menos ler e escrever, habilidades não dominadas por Preciosa.

Para, além disto, no plano emocional, como a maioria das adolescentes dessa faixa etária, a protagonista sustentava o sonho de ser famosa, sair em capas de revistas, ser adorada e glorificada pelas pessoas, sendo nas cenas em que representam a ilusão os momentos em que a protagonista aparece realmente feliz. Porém, um dos desejos, mencionado algumas vezes no decorrer da trama, diz respeito a namorar um homem branco, este fato remete às noções de racismo presentes na sociedade, à raça branca sempre pensada como um sonho. Pode-se ainda mencionar que a internalização da raça branca como superior, é construída pela educação, isto é, a escola muitas vezes perpetua um currículo que não enxerga as diferenças/diversidades, é nesta escola que nos educamos e aprendemos não apenas conteúdos escolares, mas são 
internalizados outros fatores ${ }^{6}$ que poderão vir a refletir na maneira como os indivíduos se vêem e enxergam os demais.

O filme possibilita a reflexão sobre inúmeras problemáticas sociais, como as questões de gênero, de classe social, as corporalidades, as práticas pedagógicas, e os significados da educação escolar. No que concerne a questões de gênero, pode-se mencionar o fato de que na escola alternativa, direcionada aos/às jovens que tiveram dificuldades de se adaptar ao sistema educacional, a turma na qual a protagonista faz parte é formada integralmente por estudantes mulheres. Esta observação passa indiretamente a noção de que homens são "naturalmente" mais inteligentes e não precisariam da escola alternativa. Por outro lado, identifica-se que é neste ambiente feminino que as estudantes começam a se sentir seguras para expressar sentimentos, criam vínculos afetivos, e conseguem apreender a partir da contextualização com o cotidiano. Pode-se ainda mencionar a relação de submissão da mãe de Preciosa ao seu marido, mesmo não concordando com as atitudes que ele tomava como tocar sua filha - ela alega não poder fazer nada, pois ele gostava de realizar tais ações e era o "homem" dela.

Quanto a questões de classe social, identificou-se que Preciosa e sua mãe eram dependentes da assistência social, devido a protagonista ser mãe de uma criança especial, e sua mãe não ter emprego. Durante a

\footnotetext{
6 Estudiosos do campo do Currículo nomeiam estes fatores que aparecem indiretamente no âmbito escolar como "currículo oculto", ou seja, aquele que não está explicito em documentos, mas implícito nas ações e práticas escolares.
} 
trama percebe-se que tal situação se torna bastante cômoda para a mãe de Preciosa, pois não precisava trabalhar para sustentar a casa, entregou sua neta para a bisavó criar - só a via quando a assistente social fazia as visitas - e todo o serviço de casa ficava a cargo da protagonista. Da mesma forma, a mãe de Preciosa manipulava o sistema, se arrumando e encenando, durante a visita da assistente social. De uma primeira impressão pode-se caracterizá-la como oportunista, uma parasita do governo, porém, com o desenrolar da trama, percebe-se que na verdade, toda a história de vida dessa mulher a levou até esta situação, ela já desacreditava na vida. Não tinha forças para continuar, e encontrou na hostilidade e na agressividade um meio de sobreviver, de permanecer viva.

Assim, a mãe se defendia de sua situação vulnerável atacando grupos mais estigmatizados que ela mesma, uma vez que, possuía preconceitos até com sua origem, por ser negra, considerava não ter direito a nada. Preciosa, embora não concordasse com a situação, participava e não contrariava a mãe, com o desenrolar da trama foi possível identificar que Preciosa precisou de coragem e ajuda para enfrentar a mãe e sair do programa de assistencialismo. Para Freire, o assistencialismo traz consequências para o ser humano, a longo prazo, lhe tirando a responsabilidade sobre a sua vida

Opúnhamo-nos a estas soluções assistencialistas, ao mesmo tempo em que não aceitávamos as demais, porque guardavam em si uma dupla contradição. Em primeiro 
lugar, contradiziam a vocação natural da pessoa — a de ser sujeito e não objeto, e o assistencialismo faz de quem recebe a assistência um objeto passivo, sem possibilidade de participar do processo de sua própria recuperação. Em segundo lugar, contradiziam o processo de "democratização fundamental" em que estávamos situados. O grande perigo do assistencialismo está na violência do seu antidiálogo, que, impondo ao homem mutismo e passividade, não lhe oferece condições especiais para o desenvolvimento ou a "abertura" de sua consciência que, nas democracias autênticas, há de ser cada vez mais crítica (FREIRE, 1967. p 56).

O fato de ser sujeito e não objeto de sua recuperação é revelado nos momentos em que aparece a mãe de Preciosa. A mãe é retratada sempre dentro de casa, à exceção das últimas cenas, quando ela não mais fazia parte dos programas assistencialistas, pois Preciosa havia contado a verdade à assistente social, de que sua mãe ficava assistindo televisão e comendo durante o dia todo. Isto é, ela não buscava melhorar, não procurava participar, se integrar à sociedade.

No pertinente à corporalidade, o fato de Preciosa ser uma jovem obesa, e isto ser motivo de chacotas, aparece no momento da aula na escola alternativa, quando uma das alunas menciona esta especificidade da protagonista como sinônimo de feiura. Não se identificou, durante a trama, uma preocupação enfática/neurótica de Preciosa com seu peso, embora possa-se mencionar o seu comportamento agressivo quando outros/as mencionavam essa sua característica. Em momentos de reflexão (sozinha) seu peso não aparece como a maior preocupação da protagonista, como nas suas fantasias em que sonhava com a fama, as 
representações de sua mente não alteravam seu porte físico. À exceção de um cena - em frente ao espelho - em que desejava ser branca, magra e loira, algo que pode estar relacionada às representações dos ideais eurocêntricos de beleza propalados pela mídia. Outro fato relacionado à corporalidade aparece nos momentos em que a mãe culpa a protagonista por seu pai sentir atração física por ela. Há a impressão de que ao mesmo tempo em que amava sua filha, a mãe de Preciosa sentia raiva por ela despertar o interesse de seu marido, fato esse que a impulsionava a agredir física e moralmente a filha. Podendo-se afimar que, "Em alguns momentos, a violência parece remeter à irrupção de uma força subterrânea, inconsciente, proveniente talvez de uma história de mágoas e impossibilidades de superação" (ADELMAN, RUGGI, 2011. p 213)

Diante destas características, identificou-se que o filme caracteriza-se como uma rica fonte de investigação de representações sociais, evidenciando a forma como certas ações são encaradas e vistas do ponto de vista das pessoas que as vivem, desmistificando, assim, alguns estereótipos, ao mesmo tempo em que permite a reflexão quanto a fatos recorrentes na sociedade. Dentre eles, a questão educacional, permitindo uma análise de problemáticas educacionais, como a relação professor/a - aluno/a, didáticas, metodologias de ensino e a própria linguagem como meio que permite a exclusão dentro da sala de aula. 


\section{A educação representada na produção de Lee Daniel}

Analisando as questões educacionais, foi identificado, desde o início da trama, que Preciosa era vítima de bullying pelos colegas da escola e, desta forma, não mantinha uma relação com eles/as, ficava sozinha e quieta no seu canto, não entendia o que seus/suas professores/as falavam, evidenciando uma dificuldade presente no âmbito educacional quanto à linguagem utilizada pelos professores/as, que nem sempre atingem a todos/as os/as estudantes. Segundo hooks, a linguagem é uma das formas de opressão presentes na sociedade, ao impor uma linguagem culta reprimem-se os estudantes que não têm acesso a ela, menosprezando a linguagem utilizada cotidianamente por eles/as.

As desire, language disrupts, refuses to be contained within limits. She speaks against our will, in words and thoughts that intrude, even violate the most private spaces of mind and body. It was in my first year of college I read Adrienne Rich, "The Burning of Paper Instead of Children". This poem speaks against domination, racism and class oppression, graphically illustrate tries to stop political persecution and torture of living beings is a most vital issue than censorship, than burning books. A line from the poem that moved and disturbed something inside me: "This is the oppressor's language yet I need it to talk to you" I never forgot. Maybe I could not have forgotten, even if I tried to erase it from memory. The words are imposed, are rooted in our minds against our will. The 
words of this poem led to a life in my memory that I could not abort or change. (hooks, 1994. p 167) ${ }^{7}$.

Desde a virada linguística, os estudiosos têm cada vez mais entendido a linguagem como um elemento formativo da experiência. hooks (1994) aborda o desafio de se falar radicalmente ao usar a língua do opressor. Ela fornece duas soluções possíveis para este problema: Primeiro, pode-se repensar as maneiras pelas quais usamos a linguagem, tornando-a uma linguagem de protesto. Podendo experimentar os atos de ouvir e compreender a linguagem como ferramenta do opressor, e depois "voltar a ouvi-lo como um local potencial de resistência" (1994, p.170). A segunda solução envolve a integração de outras formas de expressão, por exemplo, o vernáculo negro, na escrita formal. Embora esse processo possa ser mais difícil para aqueles/as que foram treinados para escrever na forma "culta",

7 "Como o desejo, a linguagem rompe, recusa-se a ser contida dentro de limites. Fala a si mesma contra a nossa vontade, em palavras e pensamentos que se invadem e até mesmo violam os espaços mais privados da mente e do corpo. Foi no meu primeiro ano de faculdade que li um poema de Adrienne Rich, "The Burning of Paper Instead of Children" (Queimar papel em vez de crianças). Esse poema, fala contra a dominação, contra o racismo e a opressão de classe, tenta ilustrar de modo claro que parar a perseguição política e tortura de seres vivos é uma questão mais vital do que a censura, do que queimar livros. Um verso desse poema que comoveu e perturbou algo dentro de mim: "Esta é a língua do opressor, mas preciso dela para falar com você". Eu nunca esqueci. Talvez não pudesse ter esquecido, mesmo se tentasse apagála da memória. As palavras se impõem, se enraízam na nossa memória contra nossa vontade. As palavras desse poema geraram uma vida na minha memória que eu não poderia abortar ou mudar." (Tradução da autora) 
usando uma linguagem alternativa, pode-se abrir uma série de possibilidades para aumentar a compreensão e resistir à dominação.

Além da linguagem, outras questões como a falta de respeito pelos colegas dificultavam a inserção da protagonista naquele meio. As situações presenciadas em sala de aula incomodavam Preciosa, especialmente nos momentos em que o desrespeito acontecia com um professor de matemática, único professor que admirava. Embora não apareçam outros/as professores/as além deste e da diretora, há a impressão de que o professor de matemática era o único que respeitava a protagonista, tendo como consequência a sua admiração.

Quando a segunda gravidez foi descoberta, Preciosa foi chamada à direção e expulsa da escola regular. Sendo direcionada pela diretora da escola, a uma instituição alternativa cujo lema era Each one teach one ${ }^{8}$. Em seu primeiro dia na escola alternativa, Preciosa realizou uma avaliação para verificar em que nível estava e ser direcionada a uma turma, durante a prova a protagonista apresentou dificuldades, principalmente no que se refere à leitura e a escrita, Preciosa era analfabeta aos 16 anos. Tal fato revela a imensa lacuna existente nas escolas regulares, que não percebem as dificuldades de seus/suas estudantes que passam anos como invisíveis nas carteiras escolares. Com o resultado da avaliação a protagonista foi direcionada à turma de alfabetização, lá conheceu a professora Rain, que lhe oferece uma

\footnotetext{
8 "Cada um/a ensina um/a"
} 
educação mais inclusiva e um relacionamento mais próximo e respeitoso o que, juntamente com as novas amizades, vão ajudar Preciosa a dar um rumo novo em sua vida.

$\mathrm{Na}$ escola alternativa, a metodologia era essecialmente participativa, todas as alunas participavam das atividades orais e de escrita no quadro negro. Um apontamento interessante de ser mais explorado refere-se à metodologia do diário. No filme analisado, a professora deu um diário para todas, para que colocassem o que sentiam, o que faziam e também pedia para que escrevessem estórias, com o intuito de além de refletirem sobre suas vidas, praticassem a escrita e sistematização de ideias. Além disto, a prática de exposição de seus diários às colegas - uma turma heterogênea, com estudantes imigrantes, negras, homossexuais - possibilita o compartilhamento de experiências e contato com diferentes realidades, valorizando desta forma as diversidades presentes na sala de aula.

Outras produções cinematográficas, como Escritores da Liberdade e Entre os muros da escola, por exemplo, também abordam esta metodologia com o intuito de ensinar os/as estudantes "rebeldes" a partir de suas histórias de vida. Tal prática remete a duas interpretações, uma compreende que os estudantes subversivos/rebeldes, o são devido a suas vidas, é como se a condição em que vivem e a vida que levam, fosse tão traumática que os/as levava a agir de forma descompromissada, e ao fazer com que refletissem sobre isso 
entenderiam a importância da educação e o processo de ensinoaprendizagem, desenvolver-se-ia de forma facilitada. Ou seja, quanto mais estudantes vitimados há em uma sala de aula, mais dificuldades o/a docente terá para ensinar, principalmente quando se trata de indisciplina e em instituições de segundo grau (ensino médio), pois há uma cultura, do senso comum, que prega que os/as jovens ${ }^{9}$, principalmente os/as oriundos/as da classe baixa ou pertencentes a grupos sociais estigmatizados, não "querem nada com nada", não se comprometem com assuntos importantes (para os adultos) e não possuem perspectivas de futuro. E ao se trabalhar com a sua realidade, permitindo que reflitam sobre ela, poder-se-ia permitir que estes jovens compreendessem que a única forma de se obter sucesso na vida é incorporando a cultura valorizada socialmente, ou seja, a cultura dominante.

De outro lado, identificaram-se autores como Paulo Freire, defendendo que trabalhar a partir da realidade do/a estudande permite que haja uma conscientização quanto as suas condições de vida. Fazendo-os compreender porque estão em tal situação e proporcionando reflexões para que se motivem a mudá-la. Para isso, o professor deve se

\footnotetext{
${ }^{9} \mathrm{O}$ conceito de juventude/jovens vêm sendo discutido fortemente dentro do campo educacional, segundo Dayrell (2003, p. 24) podemos entender a juventude como parte de um processo mais amplo de constituição de sujeitos, mas que tem especificidades que marcam a vida de cada um. A juventude constitui um momento determinado, mas não se reduz a uma passagem; ela assume uma importância em si mesma. Todo esse processo é influenciado pelo meio social concreto no qual se desenvolve e pela qualidade das trocas que este proporciona.
} 
utilizar, como diz Freire (1996), da corporeificação das palavras, como exemplo, e ainda destaca a importância de propiciar condições aos/às estudantes, em suas relações uns com os/as outros/as ou com o/a professor/a, de treinar a experiência de ser uma pessoa social, que pensa, se comunica, tem sonhos, que tem raiva e que ama. Com esta postura o autor quer dizer que a educação é uma forma de intervenção no mundo, que não é neutra, nem indiferente.

Freire (1996) ainda ressalta que o papel do/a professor/a é atuar como desafiador/a, capaz de promover a educação como prática de liberdade, e tem como função combater um naturalismo histórico que desconhece a historicidade do homem, como fazedor de sua própria história. O/A professor/a é aquele que possui uma prática progressista que tende a desenvolver junto aos/às estudantes uma capacidade crítica, esse/a professor/a caminha por uma direção emancipadora, consciente de constituir-se constantemente a partir de uma curiosidade construída pela superação de sua curiosidade ingênua, capaz de compreender sua função e o mundo criticamente, visando romper com "verdades" rotuladas socialmente que podem gerar preconceitos, discriminações e estereótipos. Sua postura ética deve ser compatível com suas palavras e práticas na sala de aula, já que aprendemos uns com os outros, pelo próprio exemplo. Portanto, de acordo com Freire, cabe ao/a professor/a partir da realidade do/a estudante como estratégia pedagógica, e ainda, quanto maior a diversidade de realidades presentes nas salas de aula, 
mais rico o aprendizado será. Na perspectiva da diversidade, os estudos do currículo têm contribuído significativamente para as discussões.

Pensando na diversidade presente no âmbito escolar, Gomes (2007), elabora uma análise para o Ministério da Educação referente à inserção desta no currículo. Para a autora à construção da identidade se dá a partir das relações dialógicas com os outros, e em função da mesma. Sendo a escola o espaço onde, inevitavelmente, as diferenças se encontram. Deste modo, é papel desta trabalhá-las, pois estamos inseridos em uma sociedade das diferenças, de diferentes identidades, costumes, culturas, e ao mesmo tempo em uma sociedade desigual, assim, não é possível abrir mão de um currículo multiculturalista, isto é, não se pode perpetuar um currículo que considera que apenas a existência de uma cultura, apenas um modo de ser e estar no mundo. Gomes ainda destaca, que elementos que muitas vezes passam despercebidos, como o corporal, devem ser problematizados por educadores/as, pois interferem na construção da identidade, sendo a escola um dos espaços com alto potencial para a isto.

A trajetória escolar aparece em todos os depoimentos como um importante momento no processo de construção da identidade negra e, lamentavelmente, reforçando estereótipos e representações negativas sobre esse segmento étnico/racial e o seu padrão estético. O corpo surge, então, nesse contexto, como suporte da identidade negra, e o cabelo crespo como um forte ícone identitário. (GOMES, 2002, p 41) 
Exemplo disto é encontrado nos elementos de fantasia de Preciosa, sempre relacionadas aos momentos de grande pressão ou violência, se tem a clara representação do perfil ideal de sujeito socialmente construído. Em sua imaginação, Preciosa aparece ou como uma celebridade aclamada acompanhada por um namorado branco, ou como uma garota branca, magra e com longos e lisos cabelos loiros. Como ela mesma enuncia: "Semana passada, Sra. Rain me pediu que escrevesse como eu queria ser: eu disse, cabelos longos, pele clara e magra", em outra cena, "Eu gostaria de ter um namorado com pele clara e cabelos fabulosos... eu queria ser capa de revista". Desta forma, se reforça o perfil de sujeito almejado e a vontade sempre presente de aproximação deste ideal, ainda que distante da realidade. Uma das cenas mais fortes, neste sentido, é a que mostra a protagonista em frente a um espelho, no qual a imagem refletida veste a mesma roupa e recebe os mesmos acessórios, mas é branca, magra e loira. Tem-se, assim, a reafirmação da normalidade constituída e a sua naturalização, também por parte dos indivíduos considerados desviantes. Entretanto, cabe ressaltar que o espaço ofertado na sala pela professora Rain, através de sua metodologia permitia às estudantes compreenderem suas expectativas e refletirem sobre elas, ou seja, a própria sala de aula utilizada para compartilhar os sonhos dos/as estudantes, pode ser entendida como o início de um processo de transformação. 
Imersa neste contexto, e entusiasmada com a educação, Preciosa passou a frequentar a escola alternativa regularmente, e em uma das aulas sentiu que ia ganhar seu bebê, foi direcionada a um hospital e ganhou seu segundo filho, Abdu. Suas amigas a visitavam no hospital todos os dias, levando seu diário para a professora e trazendo-o. Após receber alta, retornar para a casa e ser novamente agredida pela mãe, Preciosa arromba a porta da escola e passa a noite na sala de sua professora Rain. Este fato pode ser interpretado do ponto de vista de que a escola passou a ser um lugar de referência e/ou refugio para a protagonista, um lugar onde se sentia segura. Ainda nesta cena, é perceptível a figura da professora heroína que tenta, das mais diversas formas, ajudar suas alunas, chegando a protagonista a afirmar: " $E u$ tenho pena da senhora Rain, ela é uma professora e não uma assistente social". Mesmo com todos os esforços, a professora não pôde encontrar um lugar para Preciosa passar a noite, então a levou para sua casa, evidenciando a relação de cumplicidade e confiança estabelecida entre professora/aluna. Não apenas no plano emocional, mas também no plano educacional, pois, tanto preciosa quanto às demais estudantes, estabeleceram uma relação de confiança com a Sra. Rain e uma com as outras, quando compartilhavam a escrita de seus diários e, até mesmo, conversavam durante as aulas aconselhando-se mutuamente. Como presenciado, ao final, na cena em que, sentadas sobre as mesas e armários discutem sobre qual rumo seguirão em suas vidas. 
Mesmo com todas as situações adversas pelas quais passa, a protagonista não desiste de estudar, ela admite ter encontrado na educação uma forma de mudar a realidade à qual está inserida, e a possibilidade de dar um futuro melhor para seus filhos. Ou seja, Preciosa encontrou na educação um caminho para a sua emancipação. $\mathrm{Na}$ trama, esta cena é representada fugindo as tradicionais representações de sala de aula - cansativa, com estudantes dormindo nas carteiras - mostrando a protagonista identificando outras realidades a seu alcance, evidenciadas através de cenas colocadas como que em pequenas telas ao redor dela.

\section{Considerações Finais}

É evidente que esta obra se configura como um meio de problematizar questões presentes na nossa sociedade, como a violência doméstica, o abuso sexual por membros da família, o descaso do sistema educacional com estudantes que apresentam dificuldades de aprendizado, bem como passam por situações que interferem nesse aprendizado. E também uma visão da educação, como meio de libertação das condições em que vivem.

Igualmente, o filme faz uma crítica sutil a diversos preconceitos contra homossexuais, obesidade, raça, gênero, que podem ser 
evidenciados em diversas cenas do filme. Por exemplo, quando Preciosa revela sobre a crença de sua mãe de que homossexuais são pessoas ruins. Porém ao descobrir que sua professora, Rain, mantinha um relacionamento com outra mulher, Preciosa menciona não ser os/as homossexuais que a estupravam, muito menos que a maltratavam, evidenciando, mais uma vez, que não concordava com estereótipos perpetuados pela mãe.

Em síntese, a trama traz a jornada de uma menina por um caminho com inúmeros obstáculos, mas que nunca deixa de acreditar em um futuro melhor para si. No entanto, o desfecho do filme não revela uma Preciosa que possa ser identificada com aquela de seus sonhos, famosa e muito amada, mas uma Preciosa que ainda enfrenta diversas dificuldades, como cuidar sozinha da filha portadora de Síndrome de Down e do filho mais novo, arrumar um emprego e ter que lidar com os sintomas da AIDS - contraida nas relações sexuais forçadas com o pai -, mas que se sente capaz de dar os primeiros passos, que apresenta pequenos progressos que lhe garantirão uma vida mais estável e também mais feliz. Tal desfecho traz uma dose de realidade, o que obriga o espectador a se deparar brutalmente com a dificuldade que Preciosa enfrenta, e mesmo com todo o seu histórico de vulnerabilidade, encontra um meio para dar outro rumo a sua vida. E, embora apresente uma Preciosa mais fortalecida e capaz de viver uma 
vida mais estável, convida a encarar a realidade de que, talvez, algumas marcas da violência não possam jamais ser apagadas.

\section{Referências}

ADELMAN, M.; RUGGI, L. O. Genêro, família, e as marcas da violência em Marcas do Silêncio. In: ADELMAN, M. et al. (org). Mulheres, Homens, Olhares e Cenas. Curitiba: Ed. UFPR, 2011. p $209-224$.

BULMAN, Robert C. Hollywood goes to high school: cinema, schools, and American culture. New York, Worth Publishers, 2005.

DAYRELL, J. O jovem como sujeito social. Revista Brasileira de Educação. Set/Out/Nov/Dez 2003, n. 24, p. 40-52. Disponível em: <<http://www.scielo.br/pdf/rbe du/n24/n24a 04.pdf >> Acesso em: 17/09/2013.

FREIRE, P. A educação como Prática da Liberdade. Rio de Janeiro: Paz e Terra. 1967.

. Pedagogia da Autonomia: Saberes Necessários à Prática Educativa. Rio de Janeiro: Paz e Terra. 43ed. 2011.

GOMES, Nilma Lino. Diversidade e Currículo. In: Brasil. Ministério da Educação. Secretaria da Educação Básica. Indagações sobre o Currículo. Brasília, 2007. Disponível em: <http://portal.mec.gov.br/seb/arquivos/pdf/Ensfund/indag4.pdf>. Acesso em: 16/08/2013. p. 5 - 45 . 
Trajetórias escolares, corpo negro e cabelo crespo: reprodução de estereótipos ou ressignificação cultural? In: Revista Brasileira de Educação. n21. Set/Out/Nov/Dez, 2002. Disponível em: http://www.scielo.br/pdf/rbedu/n21/n21a03.pdf. Acesso em 20/08/2013. p. $40-51$.

GUTFREIND, Cristiane Freitas. O filme e a representação do real. In: Revista da Associação Nacional dos Programas de Pós-Graduação em Comunicação. 2006. Disponível em: http://www.compos.org.br/seer/index.php/ecompos/article/viewFile/90/90. Acesso em 22/08/2013

hooks, bell. Vivendo de amor. In: WERNECK, Jurema. et al. (orgs). O livro da saúde das mulheres negras: nossos passos vêm de longe. Rio de Janeiro: Pallas/Criola, 2000.

. Teaching To Trangress: education as practice of freedom. New York: Routouledge. 1994.

SHOHAT, E.; STAM, R. Esteriótipo, realismo e luta por representação. In:__. Crítica à imagem eurocêntrica. Cosacnaify. 2006. p 261 312 